\title{
RASGOS DE LA DEMOCRACIA ARGENTINA Eficacia de las garantías constitucionales 1983-2008: ¿división de poderes y democracia delegativa versus protección de la libertad?!
}

\author{
TRAITS OF DEMOCRACY ARGENTINA \\ Effectiveness of the 1983-2008 constitutional guarantees: \\ the separation of powers and delegate democracy versus protection \\ of freedom?
}

\author{
Raúl Gustavo Ferreyra ${ }^{2}$ \\ Profesor de Derecho Constitucional e Investigador \\ del Instituto de Investigaciones Jurídicas “Ambrosio Gioja”, \\ Facultad de Derecho, Universidad de Buenos Aires \\ rgferreyra@fibertel.com.ar
}

RESUMEN: El Derecho constitucional capta la decisión democrática del pueblo y organiza fundamentalmente dos procesos: el de la libertad y el del poder, que persiguen con piezas distintas idéntico fin: ordenar la convivencia entre los ciudadanos y facilitar la tolerancia. La democracia se realiza y actualiza merced a los procesos que deben desenvolverse dentro del marco normativo establecido por la Constitución federal. Las garantías permiten el desarrollo constitucional; sin ellas no hay derecho constitucional posible. La observación del proceso constitucional argentino 1983-2008 arroja prima facie como resultado un rendimiento más relevante de la garantía de división de poderes, aunque débil y por ende no óptimo.

PALABRAS CLAVE: Derecho constitucional. Democracia. Procesos constitucionales. División de poderes. Democracia delegativa. Garantías constitucionales. Evolución de la democracia constitucional de la Argentina.

1 Contribución presentada al X Congreso Iberoamericano de Derecho Constitucional, organizado por el Instituto Iberoamericano de Derecho Constitucional y la Asociación Peruana de Derecho Constitucional y auspiciado por el Instituto de Investigaciones Jurídicas de la Universidad Nacional Autónoma de México, Lima, Perú, del 16 al 19 de setiembre de 2009; Mesa 5: Constitución, democracia y autoritarismo. Recibida el 30 de septiembre y aprobada el 22 de octubre de 2009.

2 Doctor por la Universidad de Buenos Aires. Miembro de la Asociación Argentina de Derecho Constitucional. Consultor de la Defensoría del Pueblo de la Ciudad de Buenos Aires. 
ABSTRACT: The constitutional law captures the democratic decision of the people and organizes fundamentally two processes: that of liberty and that of power, both of which pursue with different tools the same aim: to regulate the coexistence of citizens and to foster tolerance. Democracy is realized and updated thanks to the processes that shall take place within the regulatory framework stipulated by the federal Constitution. The guarantees enable the constitutional development; without them, no constitutional law would be possible. The observation of the 1983-2008 Argentine constitutional process has resulted prima facie in a more relevant performance of the division of powers guarantee, though weak and therefore not optimal

KEY WORDS: Constitutional law. Democracy. Constitutional processes . Division of powers. Delegative democracy. Constitutional Rights . Evolution of the Argentine constitutional democracy

"Conocía la historia. Ignoraba la verdad."

CARLos Fuentes ${ }^{3}$

\section{OBSERVACIONES PRELIMINARES}

El mundo se constituye por la totalidad de las cosas que existen independientemente del conocimiento es un enunciado razonablemente argumentable, difícil de controvertir y elemental para el sentido común. Naturalmente, el Derecho constitucional es un existente mundano (Russell, Bertrand, 1999, pp. 66-74). Por ello, conocer el Derecho o sistema constitucional (V. Bidart Campos, Germán, 1995, pp. 19-24) implica la comprensión previa de su objeto: las reglas de raíz y jerarquía constitucional. Solamente a partir de dicha comprensión, es decir a partir de una correcta configuración ontológica del objeto, se pueden formular atribuciones de la cosa. (V. Bunge, Mario, 1981, pp. 50-61.)

Consecuentemente, desde que la normatividad de un sistema constitucional no es sino la de un orden histórico concreto, la única cuestión que merece ser planteada en el contexto de la exposición es la relativa a las disposiciones normativas contenidas en el sistema constitucional de la Argentina actual, individual y concreto. (V. Hesse, Konrad, 1992, pp. 3-29.)

Sobre el método. Corresponde distinguir, pues, entre la descripción del objeto (el Derecho positivo constitucional) y, luego, su valoración. Lógicamente, resulta indiscutido, que, para poder criticar, previamente, hay que conocer la cosa, en este caso, los rasgos básicos del sistema constitucional federal de la Argentina.

3 Fuentes, Carlos. (2006). Los años con Laura Díaz, $2^{\text {a }}$ edición, (Madrid,Punto de Lectura), p. 9. 


\section{§ II. AFIRMACIONES BÁSICAS}

A continuación, las proposiciones capitales (V. Popper, Karl, 1995, pp. 61-82) que se discuten y desarrollan en esta disertación. No es mi intención elaborar conceptos constitucionales meta-positivos. Apoyo las afirmaciones sobre las expresas disposiciones normativas creadas por el poder constituyente y su desenvolvimiento en la experiencia constitucional.

Primera. La constitución escrita del Estado argentino es un modelo normativo que, naturalmente, como es dable esperar de toda obra humana, experimentará intentos de modificación, quebrantamiento o transgresiones en su continuidad histórica. Es justificable aseverar que la constitución vale o valdrá, lo que valen o valdrían sus garantías.

Segunda. La Declaración de los Derechos del Hombre y del Ciudadano de 1789 estipuló, en su artículo 16: "Toda sociedad en la cual no esté establecida la garantía de los derechos, ni determinada la separación de los poderes, carece de Constitución”.

Si bien es cierto, que resulta complejo imaginar la existencia de la garantía de los derechos individuales sin separación en el ejercicio de la funciones estatales, si se examina el período 10/12/1983-10/12/2008, 25 años de democracia constitucional en la Argentina que se han cumplido muy recientemente, se puede proyectar, que, las garantías denominadas estructurales del sistema constitucional han tenido, por decirlo de algún modo, un rendimiento más distinguido que las garantías de los derechos individuales. La primera vez en 155 años de historia constitucional en que todos los ciudadanos sin interrupciones durante 25 años han podido y pueden participar del proceso de gobierno; con simulacros, debilidades y frustraciones, pero participación al fin de cuentas.

Tercera. Un nivel de argumentación derivado del anterior, o sea, proyectado por el funcionamiento de la Constitución de la Argentina como proceso, pero sin controles horizontales, da lugar a nuevo animal político: la democracia delegativa. (V. O'Donnell, Guillermo, 1997, 287-304.) Se basa en la premisa de que la persona que gana la elección presidencial se encuentra autorizada a gobernar como a él o a ella crea conveniente, solo restringida por la cruda realidad de las relaciones de poder existentes y por la limitación constitucional del término de su mandato.

Distingo, pues, la regulación de un orden constitucional concreto y la comprensión que efectivamente ha realizado, teniendo en mira el interrogante planteado en la apertura; es decir, importante, significa, una cualidad o atributo, algo que se atribuye a un objeto porque es muy interesante.

Sin que implique una afirmación anticipada, corroborar, que la Constitución federal de la Argentina -en adelante: CA de modo indistinto- ha mostrado una mayor distinción en tanto regulación y garantía del proceso de gobierno, no trae como consecuencia inmediata desmentir que la Ley Mayor carezca de una ideología o valores sustantivos. En todo caso, los procesos de gobierno (V. Ely, John Hart, 1997, pp. 97-131) 
estipulados en la Constitución vislumbran un funcionamiento más adecuado a la letra constitucional que las garantías de los derechos individuales, que, muchas veces, deben verse cara a cara contra el despotismo ilustrado de la razón de estado.

Apréciese, ahora, un aspecto conceptual del título del trabajo. Por amor a la claridad y sin perjuicio de que se volverá más adelante, con el objeto de asegurar la demarcación de la propuesta, por garantía constitucional se han de captar aquellos instrumentos diseñados para acortar las orillas que habitualmente separan lo ordenado por la prescripción enunciada en el texto constitucional y el sentido que la práctica de las autoridades a cargo del gobierno pueda aplicarle incorrectamente. Por división de poderes de modo analítico debe recordarse que en todo Estado constitucional se individúan tres tipos básicos de tareas: legislativa, producción de reglas generales que contienen requerimientos dirigidos a la conducta humana; ejecutiva, en su ejecución para lograr finalidades colectivas; y, judicial, asegurar el respeto y reintegración de las reglas violadas, especialmente en casos de conflictos entre sujetos de derecho. (V. De Vergottini, Giuseppe, 2005, pp. 67-96.) Y por eficacia si una regla es o no es cumplida por las personas cuyo requerimiento de conducta se dirige y, en el caso de ser violada, que se la haga valer con medios coercitivos por la autoridad que la impuesto. (V. Bobbio, Norberto, 1997, pp. 20-38.)

\section{§ III. REGLA BÁSICA}

\section{Constitución y garantías}

Ciertamente, cada sistema constitucional posee sus propios rasgos de identidad. Posiblemente pueden hallarse formulaciones de disposiciones normativas de manera parecida en diversos textos constitucionales. Pero, la identidad finaliza allí, en el lenguaje. Porque cada orden institucional provoca y proyecta frutos y malestares diferentes sobre la realidad política, la que es influenciada decisivamente por el ámbito cultural de la comunidad. (V. Häberle, Peter, 2003 (a), pp. 223-245.)

La Constitución federal de la Argentina, con aciertos y errores, se ha afirmado, a nivel dogmático, como la Ley Mayor del sistema jurídico que pretende canalizar las expectativas de la sociedad para estabilizarlas y brindarles permanencia. Manteniéndome en esta posición, además, sostengo que, aunque los padres fundadores diferían o no coincidían acerca de cuán democrática sería la Constitución, está fuera de duda que, más de 150 años después, dicha Ley Mayor -garantizando la participación libre, igual y plural de todos los ciudadanos sometidos a ella- ha juridificado la democracia.

Actualmente, el orden estatal de la República Argentina se encuentra instituido por su Derecho constitucional, creación humana que emana básicamente ${ }^{4}$ de las re-

4 El sistema jurídico constitucional es básicamente objeto de interpretación porque su delimitación viene determinada por la fuente de producción constituyente. En contadísimas ocasiones también el Derecho 
glas generales contenidas en la Constitución federal de 1853 con sus reformas de 1860 -la constitución histórica-, 1866, 1898, 1957 y 1994 y en las reglas del Derecho internacional de los derechos humanos que gozan de jerarquía constitucional. La primacía del Derecho internacional de los Derechos Humanos -en adelante DDHH- puede ser observada como un paradigma del Derecho constitucional de la Argentina. ${ }^{5}$

Defender que la Constitución federal es cauce de un poder constituyente democrático, implica, además, sostener la existencia de un diálogo intergeneracional. El único modo democráticamente aceptable de justificar la idea de "constitución", es entenderla como un proceso público.

La Constitución federal de 1853-60, con importantes reformas mantiene su vigencia, fijando el techo jurídico y valorativo de la comunidad estatal.

constitucional es producto de la interpretación judicial, por obra y gracia de la generalidad normativa de la disposición elaborada por el juez para justificar su decisión, la que no fue prevista por el constituyente. Sobre esta cuestión, remito a mi contribución "Rasgos básicos del Derecho constitucional: sistema; libertad, igualdad, fraternidad; teoría”, en vías de publicación Revista de Derecho Político, Madrid, 2009. La creación judicial de Derecho (constitucional) se produce, exclusivamente, en los casos de lagunas normativas y en los de conflictos de reglas -falta de plenitud y de coherencia, respectivamente- motivo por el cual sostener que las sentencias judiciales son normas individuales constituye una afirmación más que dudosa. Consecuentemente, fuera de los citados casos que exponen defectos del sistema, es dudoso que las llamadas "normas o reglas individuales -sentencias-" que parecen requerir el rasgo inequívoco de la generalidad, al menos respecto del sujeto o destinatario de la norma o regla, sean realmente "normas o reglas" constitucionales stricto sensu. (V. BuLıry, Eugenio, 2003, pp. 21-37).

5 Por intermedio de la reforma constitucional de 1994 se dispuso en el artículo 75, inciso $22^{\circ}$ “...Corresponde al Congreso... inciso $22^{\circ}$ : Aprobar o desechar tratados concluidos con las demás naciones y con las organizaciones internacionales y los concordatos con la Santa Sede. Los tratados y concordatos tienen jerarquía superior a las leyes. La Declaración Americana de los Derechos y Deberes del Hombre; la Declaración Universal de Derechos Humanos; la Convención Americana sobre Derechos Humanos; el Pacto Internacional de Derechos Económicos, Sociales y Culturales; el Pacto Internacional de Derechos Civiles y Políticos y su Protocolo Facultativo; la Convención sobre la Prevención y la Sanción del Delito de Genocidio; la Convención Internacional sobre la Eliminación de todas las Formas de Discriminación Racial; la Convención sobre la Eliminación de todas las Formas de Discriminación contra la Mujer; la Convención contra la Tortura y otros Tratos o Penas Crueles, Inhumanos o Degradantes; la Convención sobre los Derechos del Niño; en las condiciones de su vigencia, tienen jerarquía constitucional, no derogan artículo alguno de la primera parte de esta Constitución y deben entenderse complementarios de los derechos y garantías por ella reconocidos. Sólo podrán ser denunciados, en su caso, por el Poder Ejecutivo nacional, previa aprobación de las dos terceras partes de la totalidad de los miembros de cada Cámara. Los demás tratados y convenciones sobre derechos humanos, luego de ser aprobados por el Congreso, requerirán del voto de las dos terceras partes de la totalidad de los miembros de cada Cámara para gozar de la jerarquía constitucional ".

La ley 24.820 -publicada en el Boletín Oficial del 29/5/1997- otorgó jerarquía constitucional a la Convención Interamericana sobre Desaparición Forzada de Personas, aprobada por la XXIV Asamblea General de la OEA, en los términos del artículo. 75, inciso $22^{\circ}$ de la Constitución federal. La ley 25.778, publicada en el BO el 3/9/2003, otorgó jerarquía constitucional a la Convención sobre la Imprescriptibilidad de los Crímenes de Guerra y de los Crímenes de Lesa Humanidad, adoptada por la Asamblea General de la ONU el 26/11/1998 y aprobada por ley 24.584 .

Consecuentemente, hoy, 13 instrumentos del DDHH gozan de jerarquía constitucional. 
La Ley Fundamental marca un vital punto de inflexión en la historia de la democracia argentina. Porque revela el paso último -no final- del proceso de construcción política del Estado, cuya semilla fue sembrada por la gesta revolucionaria de 1810 , seguida de la declaración de la independencia el 9 de julio de 1816 y los intentos constitucionales de 1819 y 1826 . Y también porque estructura las bases para el apoyo y arranque de todo el edificio estatal, cuyos antecedentes fundantes e inmediatos fueron el Pacto Federal de 1831, el Acuerdo de San Nicolás de los Arroyos de 1852 y el magnífico proyecto constitucional surgido de la pluma de Juan Bautista Alberdi. (V. Alberdi, Juan Bautista, 1856).

El Estado constitucional de Derecho argentino se explicita como el resultado de cierto marco consensual entre integrantes -no todos los integrantes- de una comunidad, en un principio libre, que acordaron expresar los vínculos estrictamente necesarios y mínimos para el desenvolvimiento de la coexistencia pacífica y perdurable. La CA, en su cuerpo textual, contiene la expresión de ese consenso puesto de manifiesto por los contrayentes. Nada más ni nada menos.

La Ley Fundamental argentina, jurídicamente, es un pre-compromiso para una aceptación generalizada; todas, absolutamente todas las ramas del Derecho positivo en vigor encuentran su último -y su único- fundamento en ella, debiéndose dejar constancia, además, de la jerarquía constitucional conferida al Derecho Internacional de los derechos humanos (cfr. arg. artículo 75, inc. 22 de la CA).

La Constitución federal es, ante todo y sobre todo, una regla jurídica.

La Constitución federal es ley suprema del sistema jurídico, a condición de que su vulneración o quebrantamiento no sólo puedan ser considerados prácticas antinormativas, sino también ineficaces. Consecuentemente, la fuerza normativa de la CA, es decir su verdadera eficacia, depende centralmente de la planificación de sus propias garantías. Dada su posición en el sistema jurídico, la Constitución se protege a sí misma o no la protege nadie ni nada!

Una rigurosa concepción de las garantías constitucionales permite visualizarlas como las herramientas para hacer efectivas íntegramente las pautas del sistema jurídico constitucional, en cualquier circunstancia de modo, tiempo y lugar, frente a cualquier voluntad o fuerza, por poderosa o enérgica que sea.

Defender la constitución, misión para la que son concebidas las garantías, consiste básicamente en protegerla contra las transgresiones o tentativas de quebrantamiento. Tales prácticas especialmente pueden provenir de las autoridades a cargo de los poderes constituidos del Estado, designadas, paradójicamente, para hacer cumplir de modo estricto sus disposiciones.

Garantías constitucionales es un concepto extremadamente amplio, motivo por el cual dentro de tal categoría quedan comprendidas: las garantías de la constitución; las 
garantías de los derechos constitucionales; la garantía orgánica del Defensor del Pueblo y, por último, la garantía de acceso a la jurisdicción supranacional.

\section{Garantías constitucionales}

\section{A. Garantías de la Constitución}

La concepción de las garantías de la constitución remite a una idea nuclear: que la política debería de ser constitucionalmente adecuada, descartándose de plano la posibilidad de que la constitución pueda ser políticamente adaptada, según el paladar o antojo de quienes representen circunstancialmente la voluntad del cuerpo electoral.

El examen del sistema constitucional federal de la Argentina permite la siguiente ilustración de piezas que componen el subsistema denominado garantías de la constitución:

i. División de las tareas de los poderes constituidos. La separación, la organización y el equilibrio de las funciones de los poderes del Estado, con la finalidad exclusiva de limitar el poder y que los gobernantes se sometan a los postulados normativos establecidos en la Ley Fundamental (v. en este sentido, por ejemplo, arts. 1, 29, 33, 44, 87 y 116 de la Constitución federal de la Argentina).

ii. Reforma constitucional. El proceso de reforma de la Constitución federal se enuncia en el artículo 30 constitucional. Quizá podría entenderse, no sin razón, que el cambio constitucional atraparía a todos los sucesos y procesos que pueden sufrir los textos constitucionales, en el tiempo. No obstante, rigurosamente, el cambio sobre el que se teoriza es el "cambio formalizado" del sistema normativo constitucional, que implica la modificación de su texto producida por acciones voluntarias, intencionadas y regladas por la propia Ley Mayor. En tales condiciones, al hablarse de reforma constitucional ésta puede consistir en: a) expansión: cuando se agrega una disposición al conjunto; b) contracción: cuando se elimina alguna disposición normativa de la nómina de ese conjunto; c) revisión: cuando se elimina alguna disposición normativa y luego se agrega otra incompatible con la eliminada. Se trata, en rigor, de un "proceso formal de aprobación".

iii. Emergencias y autodefensa constitucional. El plan de emergencias básico del Derecho Constitucional del poder: (a) declaración del estado de sitio, cfr. arg. arts. 23 y 75, inc. 29, de la Constitución federal; (b) intervención federal a las provincias y la Ciudad de Buenos Aires, cfr. arg. arts. 5 y 75, inc. 31; (c) también cabe incluir en esta dimensión garantista al imperio de la Constitución aun cuando se interrumpiere su observancias por actos de fuerza contra el orden institucional y el sistema democrático. Dicha regla, que fulmina con nulidad a los actos censurados, milita, regiamente, en el artículo 36 constitucional; quizás, una nueva versión de democracia militante. (V. Torres del Moral, Antonio, 2006, pp. 209-224).

iv. Desarrollo progresivo de los derechos subjetivos constitucionales por intermedio de la reglamentación a cargo del Congreso. Comportan igualmente una garantía de la constitución, bajo la óptica desde la cual se viene describiendo en este apartado, 
las reglas constitucionales que aseguran que la zona periférica de los derechos fundamentales será reglamentada, si fuere necesario, exclusivamente por ley emanada del órgano legislativo. Así, por ejemplo, las atribuciones legislativas que la Constitución federal de la Argentina confiere al Congreso en los arts. 75, 28 y concordantes de la Constitución federal. Copiosa jurisprudencia de la Corte Suprema de Justicia de la Nación -en adelante, CSJN, indistintamente- se inscribe en tal orientación. V. en tal sentido, por ejemplo, la doctrina registrada en Fallos: 312: 496 "Portillo, Alfredo s/ infracción art. 44 ley 17.531" (1989), entre muchos otros.

v. Estándar de racionalidad, mínimo aceptable, y función republicana. Los principios que estipulan y precisan un ejercicio racionalmente justificable de los poderes del Estado, exigiendo un mínimo estándar de razonabilidad en los actos de funcionarios a cargo de las distintas ramas del gobierno republicano (arts. 1, 28 y 33 de la Constitución federal).

vi. Control del Congreso. La distinta gama de controles políticos del Congreso se encuentra prescripta en la Constitución Federal de la República Argentina en los arts. 53 , 59 y $60 ; 99$, inc. 3 , y $11 ; 75$, inc. $8,22,25,26,21 ; 29 ; 31 ; 32 ; 71 ; 104 ; 101 ; 83 ; 76$ y 100 , inc. 12 .

A cargo exclusivo del Senado: art. 99, inc. 4, 7 y 19 de la CA.

vii. Federalismo. Desde el punto de vista de las reglas constitucionales, el estado federal argentino consiste en un reparto de competencias entre las autoridades del gobierno federal y las autoridades de los gobiernos de los estados locales, que se ajusta al artículo 121 constitucional: "las provincias conservan todo el poder no delegado" por la Constitución "al gobierno federal" y el que "expresamente se hayan reservado por pactos especiales al tiempo de su incorporación”. La Constitución federal es la norma abarcadora y suprema de todos los órdenes: federal, provincial y municipal. Cada uno de estos órdenes, a manera de parcialidades, forman parte de la Constitución la que los crea y dimensiona, considerándolos como parte de un sistema que de ella nace. Se trata de la división vertical del poder del estado, artículos 1, 28, 29, 31, 33 y Segunda Parte de la Constitución federal. (V. Vanossi, Jorge, 2000, pp. 451-474).

2. B. Garantías de los derechos constitucionales.

Con idéntica jerarquía que las garantías del derecho de la constitución, la esencia misma de las garantías de los derechos constitucionales queda constituida por la técnica jurídica especializada para dotar de efectividad a los derechos. Desde otro ángulo, pueden ser definidas como las herramientas de naturaleza reactiva y defensista que se ofrecen a los habitantes para que, en cada caso singular o general en que se repute producida una vulneración o amenaza de lesión de un derecho fundamental puedan acudir a ellas y obtener la preservación del derecho.

Enrolándome -insisto- con fines exclusivamente de naturaleza práctica, a continuación se realiza una enumeración de las garantías individuales que ofrece el sistema normativo constitucional argentino: 
La garantía de acceso a la jurisdicción: el debido proceso legal (arts. 17 y 18 de la CA).

Acción constitucional de amparo (art. 43 de la Constitución federal y art. 25 del Pacto de San José de Costa Rica).

Acción constitucional de habeas data (art. 43 de la Constitución federal).

Acción constitucional de hábeas corpus (art. 43 de la CA).

Inviolabilidad del domicilio, de la correspondencia y de los papeles privados.

Jueces naturales. Prohibición de comisiones especiales. Prohibición de la confesión coercitiva (art. 18 de la Constitución federal).

(a) Principio de legalidad en materia penal. Irretroactividad de la ley penal. Retroactividad de la ley penal más benigna. Información del hecho imputado. (b) Presunción de inocencia. (c) Condiciones para la validez de la confesión del imputado. Inmunidad de la declaración del imputado. (d) Libertad provisional: excarcelación y eximición de prisión. (e) Defensa técnica: comunicación entre el inculpado y su defensor. (f) Detención de personas, principio general: arresto sólo por orden judicial escrita. (g) Publicidad del proceso penal. (h) Peculiaridades del derecho de defensa y debido proceso: garantía de la doble instancia para recurrir el fallo ante juez o Tribunal Superior. Garantía a la asistencia letrada en proceso penal. (i) Indemnización por indebida privación de libertad. (j) Non bis in idem o garantía contra el doble juzgamiento. (k) Derecho del imputado a obtener un pronunciamiento que ponga término del modo más rápido posible a la situación de incertidumbre y de innegable restricción de libertad que puede comportar el enjuiciamiento penal. (l) Garantías constitucionales para la ejecución de la pena: cárceles sanas y limpias; prohibición de la pena de muerte; prohibición de tormentos, azotes y penas o tratos crueles, inhumanos o degradantes (cfr. arg. arts. $1^{\circ}, 18,19,28$ y 33 de la CA y 7, 8, 9 y 10 de la Convención Americana de Derechos Humanos -en adelante CADH-y 9, 10, 11, 14 y 15 del Pacto Internacional de Derechos Civiles y Políticos).

La excepción o defensa de inconstitucionalidad es una de las defensas más importantes y gravitantes de la que dispone el justiciable en el ámbito del Derecho federal argentino para peticionar, en cualquier proceso judicial, y exigir que se excluya a su respecto la aplicabilidad de un acto o norma que se encuentre infringiendo la Constitución federal, llevándose adelante el correspondiente control normativo, del cual puede derivar la declaración de inconstitucionalidad del producto jurídico sometido a juicio de revisión.

\section{C. Entreacto.}

Interpretación y control judicial de la constitucionalidad.

Una constitución jurisdiccionalmente garantizada es, presumiblemente, el paradigma de las garantías de la constitución. La garantía jurisdiccional de la constitución puede ser razonablemente entendido como el mecanismo jurídico-institucional que mayor aptitud reviste para garantizar que la constitución se mantenga como la norma suprema del sistema jurídico estatal.

Además, la garantía jurisdiccional posibilita al Estado que por su intermedio pueda asegurar la estructura jerárquica de su sistema jurídico. La garantía jurisdiccional de la 
constitución merece ser encuadrada tanto en el plano de las garantías del derecho de la constitución como en el de las garantías constitucionales para la defensa de los derechos constitucionales en particular.

Garantiza la supremacía constitucional, pero en virtud del modo de control difuso sus efectos solamente implican el caso concreto.

2. D. Garantía orgánica para la defensa de los derechos fundamentales: el Defensor del Pueblo

La reforma constitucional de 1994 confirió status constitucional al Defensor del Pueblo, cfr. arg. art. 86 de la Constitución federal. Igualmente, le vale el calificativo de garantía orgánica, a falta de otro mejor. Su misión es la defensa de los derechos fundamentales. Tarea para la cual se lo legitima procesalmente por intermedio de la regulación constitucional.

2. E. Garantía supranacional para la defensa de los derechos fundamentales estatuidos por el derecho de la constitución

La reforma constitucional de 1994 confirió rango constitucional a las disposiciones de la CADH, de conformidad a lo estipulado en el art. 75, inc. 22, de la CA. Afirmando una tendencia iniciada en 1984, luego de la reforma de 1994 la jurisdicción constitucional en materia de protección de los derechos fundamentales ha dejado de pertenecer exclusivamente al Estado argentino, en razón de que puede acudirse a la jurisdicción supranacional para perseguir la restauración de una regla jurídica tutelada por la CADH. Tal hipótesis no es ni habitual ni ordinaria, y sólo procede una vez que se encuentran reunidos una serie de rigurosos recaudos, entre los que ocupa el primer rango el de la interposición y agotamiento de los recursos previstos al respecto por la esfera jurisdiccional estatal interna, conforme a los principios del Derecho Internacional generalmente reconocidos. Con cierta licencia, puede predicarse también desde un punto de vista débil que la jurisdicción organizada para la defensa de los derechos fundamentales es concurrente, ya que la facultad de reclamar la tutela sobre la base de los mecanismos de protección previstos por la Convención autoriza tal aseveración. Es en tal línea de acción, entonces, donde se sostiene que el acceso a la jurisdicción supranacional configura una garantía para la defensa de los derechos constitucionales.

Además, el Estado argentino puede solicitar a la Corte Interamericana una opinión consultiva sobre la compatibilidad entre cualquiera de las leyes internas del Estado y la $\mathrm{CADH}$ u otro tratado concerniente a la protección de los DDHH.

\section{Excursus sobre eficacia de las garantías}

Es intención fijar lineamientos para la comprensión teórica del sistema constitucional argentino, haciendo hincapié en el desempeño de las garantías. Ellas son, a mi juicio, inseparables del significado de constitución. Así, la constitución será verdaderamente la nave insignia del sistema jurídico, siempre que las garantías tengan aptitud para respaldar sus propias prescripciones regladas. 
Las garantías pueden ser eficaces o ineficaces, pero son siempre imprescindibles para reducir la brecha entre la prescripción de la Ley Fundamental y el acto o norma del servidor público. A veces lo logran. Otras veces, su ineficacia queda patentizada, originándose un proceso capaz de quebrantar la correcta estructuración del Derecho Constitucional.

El problema de la eficacia o ineficacia de las garantías constitucionales es, sustancialmente, si ellas son aptas o no para poner en funcionamiento los mecanismos susceptibles de originar que, en caso de incumplimiento, las disposiciones constitucionales sean observadas por las personas a quienes se dirigen.

La concepción de las garantías de la constitución remite a que la política sea genuinamente constitucional, tanto en su génesis como en su desarrollo", es decir, que las decisiones políticas se elaboren y ejecuten en virtud del marco que estatuye la constitución, y no al revés. Los mecanismos descritos tienen como destinatario exclusivo a los poderes públicos. Si por política ha de entenderse, siguiendo a Bertrand Russell (Russell, Bertrand, 2004, 130-142) la producción de los efectos proyectados o deseados sobre otros hombres, las garantías de la Constitución son básicamente, garantías políticas: la Constitución garantiza el pacto democrático fundamental; establecida la Constitución, las garantías políticas consisten en las relaciones reales de poder existentes entre los órganos políticos organizados y aspiran a tutelar la división vertical y horizontal del poder y los frenos y contrapesos recíprocos.

La conexión entre las garantías de la Constitución con las garantías de los derechos constitucionales es evidente, en virtud que, la constitución como norma jurídica no encierra una finalidad en sí misma, sino que es una herramienta privilegiada para garantizar la vida, la libertad, la propiedad y la seguridad personal a los ciudadanos.

Las garantías de la Constitución operan en cierto modo como presupuestos de las garantías de los derechos constitucionales, porque las primeras posibilitan la vigencia de la supremacía constitucional, la que es indispensable para generar la plataforma que requieren las segundas, para así poder arrancar. No parece razonable negarse a reconocer que cuando una persona pide el amparo de alguno de sus derechos, no está sólo peticionando el respeto de una prerrogativa individual, social o grupal que el texto constitucional le confiere, sino además -y si se prefiere indirectamente-, ejerciendo un derecho implícito a que la constitución se mantenga y conserve. Puede subrayarse, entonces, que cuando una persona reclama que se garantice un derecho, cuyo reconocimiento confiere el texto de la constitución, también se estará defendiendo la constitución, ya que es propiamente el principio de supremacía de ley fundamental quien le discierne y adjudica la disponibilidad de la acción en su defensa; que de otro modo no podría operar.

Las garantías de los derechos son, básicamente, garantías jurídicas: se distinguen de las políticas en tanto sus efectos son susceptibles de cálculo seguro; lo que puede no serlo es saber si van a ser o no reconocidas en casos particulares, si son suficientes 
en sus disposiciones concretas, si se las aplicará en todas las circunstancias; pero estas son deficiencias que acompañan a todo hacer humano. Las garantías jurídicas, dependen, en última instancia, de la interpretación judicial para su aplicación.

En cualquier caso, y para realizar una afirmación bien corta: las garantías políticas, las garantías de la Constitución, protegen, sustancialmente, la producción del Derecho; en cambio, las garantías jurídicas, tutelan, primordialmente, la aplicación del Derecho. Es dable reconocer que la primera defiende un particular poder normativo, de alcance general; no ocurre lo mismo con las segundas, que se dirige a casos individuales, en ningún caso, generales. ${ }^{6}$

\section{§ IV. LA PRIMACÍA (RELATIVA) DE LAS GARANTIIAS POLÍTICAS}

La Constitución federal de la Argentina es una constitución liberal.

Liberal, en el sentido que su finalidad originaria es la garantía de la libertad.

Para concretar la idea fundamental de la libertad, se deducen dos consecuencias presentes como piezas elementales de la Ley Mayor de la Argentina: la regla de distribución importa un ámbito de libertad del ciudadano que se supone anterior al Estado, quedando la libertad del individuo ilimitada como pauta regia, mientras que la facultad del Estado para invadirla es limitada; y la regla de organización, que significa que el poder del Estado se divide y encierra en un sistema de competencias tan detallada como determinadas y circunscriptas. (V. Schmitt, Carl, 1992, pp. 137-148.)

\section{La distribución: la libertad constitucional}

Antes de visualizar, estrictamente, cuál ha sido el rendimiento de la defensa de la libertad, corresponde deslizar el concepto básico sobre la libertad jurídica.

Apropiadamente, la libertad como regla genérica se refleja en el Preámbulo de la Constitución federal de la Argentina, que propone como uno de los contenidos del fin del estado: “... asegurar los beneficios de la libertad...”.

6 Nótese que Karl Loewenstein distinguió en el proceso del poder, en términos de controles verticales y horizontales; entre los controles verticales fijó al federalismo y a las garantías individuales; por su lado, entre los horizontales, básicamente, a la división del poder. (LOEWENSTEIN, Karl, 1979, pp. 233-236, 354360 y 390-421). He dado tratamiento detallado en la obra Notas sobre Derecho constitucional y garantías, $2^{a}$ edición, Porrúa, México, 2004, pp. 77-131, donde remito en homenaje a la brevedad. Sin embargo, se pone de manifiesto, que la decisión de plantear el tema y problema de las garantías constitucionales fijando el horizonte de proyección en la naturaleza productiva o aplicativa del Derecho, tiene que ver, especialmente, en la originalidad de la disertación, impregnada, ciertamente, por una decisión gnoseológica del autor, que sin deslucir ni devaluar el criterio de Loewenstein, lo tiene presente, pero se presenta con otra estructura y una dimensión que provoca otros efectos. 
La libertad constitucional comporta diversos aspectos:

Un status personal que depare al hombre la calidad de sujeto de Derecho, cuya negación es la incapacidad de Derecho o la esclavitud. El artículo 15 constitucional, al abolir la esclavitud, mantiene virtualidad presente para afianzar esta regla, porque si no pueden existir esclavos, todo hombre es persona jurídica. Por su parte, los arts. 1 y 3 de la Convención Americana sobre Derechos Humanos y el artículo 16 del Pacto Internacional de Derechos Civiles y Políticos prescriben que todo ser humano tiene derecho al reconocimiento de su personalidad jurídica.

Un área de intimidad neutra o inofensiva para el grupo o para terceros, quede inmunizada y sustraída a toda interferencia del Estado. Es la fórmula del artículo 19 constitucional: las acciones privadas de los hombres que de ningún modo ofendan al orden y a la moral públicas ni perjudiquen a un tercero, están solo reservadas a Dios y exentas de la autoridad de los magistrados.

Una regla básica, una suerte de regla de clausura del sistema: todo se encuentra permitido, excepto, naturalmente, lo que se encuentra expresamente prohibido. Esta interpretación se deduce, claramente, del artículo 19 constitucional: porque si nadie puede ser privado de hacer lo que la ley no impide, es porque lo no prohibido está permitido. Si fuese necesario que las permisiones, todas, debieren estar habilitadas, se perderían hasta el infinito, tornando irracional el sistema constitucional.

Políticamente libre es el individuo que se encuentra sujeto a un sistema jurídico, en cuya creación participa, tan siquiera en nimia medida. (V. Kelsen, Hans, 1958, pp. 335-360.)

La Constitución federal garantiza la libertad de elegir y ser elegido, plenamente, con arreglo al principio de soberanía popular. La Convención Americana sobre Derechos Humanos, en su artículo 23, garantiza que todos los ciudadanos puedan participar en la dirección de los asuntos públicos, directamente o por medio de representantes libremente elegidos; b) de votar y ser elegidos en elecciones periódicas auténticas, realizadas por sufragio universal e igual y por voto secreto que garantice la libre expresión de la voluntad de los electores, y de tener acceso, en condiciones generales de igualdad, a las funciones públicas de su país.

La libertad constitucional de cada hombre está limitada por la libertad de los demás, por la seguridad de todos y por las justas exigencias del bienestar general y del desenvolvimiento democrático. Regiamente, regla esta cuestión, el artículo 23 de la Declaración Americana de los Derechos y Deberes del Hombre.

Todos estos aspectos de la libertad coinciden con la base de legitimación del Estado, el que no debe empeorar las condiciones de vida de los habitantes y permitir su libre participación en la construcción estatal. 


\section{La organización}

La garantía política de la división de los poderes estatales tiene por inocultable finalidad contribuir a la consecución de lo que cotidianamente parece imposible, o digno de una de las más fantásticas de las utopías: someter el poder al cumplimiento de reglas de juego jurídicas preestablecidas.

La garantía apunta a impedir la concentración de los poderes. La garantía de la división de poderes, al menos en teoría, pone de manifiesto un principio novedoso en la vida y desenvolvimiento de las grandes comunidades humanas: que el fraccionamiento del poder del Estado era -y es- un formidable escudo de protección para la libertad de los habitantes.

Montesquieu, a quien puede asignarse la paternidad de la teoría de la división de poderes, concretó la misma sistematizando, posiblemente, sus experiencias sobre la vida política en Gran Bretaña. Oigamos al propio Montesquieu: “... Hay en cada Estado tres clases de poderes: el Poder Legislativo, el Poder Ejecutivo de los asuntos que dependen del "derecho de gentes" y el Poder Ejecutivo de las cosas que dependen del derecho civil. Por el poder Legislativo, el príncipe o el magistrado promulga leyes para cierto tiempo o para siempre, y enmienda o deroga las existentes. Por el segundo poder dispone de la guerra y de la paz, envía o recibe embajadores, establece la seguridad, previene las invasiones. Por el tercero, castiga los delitos o juzga las diferencias entre particulares. Llamaremos a éste Poder Judicial, y al otro, simplemente, Poder Ejecutivo del Estado. La libertad política de un ciudadano es la tranquilidad de espíritu que proviene de la confianza que tiene cada uno en su seguridad: para que esta libertad exista, es necesario un gobierno tal que ningún ciudadano pueda temer a otro..." (V. Montesquieu, circa 1900, p. 224.)

Una vez estipulados los tres poderes constituidos, Montesquieu articulaba su máxima, con el tiempo convertida en célebre regla del Estado liberal: cuando el poder legislativo está unido al Poder Ejecutivo en la misma persona o en el mismo cuerpo, no hay libertad, porque se puede temer que el monarca o el Senado promulguen leyes tiránicas para hacerlas cumplir tiránicamente. Tampoco hay libertad si el Poder Judicial no está separado del legislativo ni del ejecutivo. Si va unido al Poder Legislativo, el poder sobre la vida y la libertad de los ciudadanos sería arbitrario, pues el juez sería al mismo tiempo legislador. Si va unido al Poder Ejecutivo, el juez podría tener la fuerza de un opresor.

La teoría de la separación de las funciones de los poderes del Estado, si bien fue inventada en Europa, se plasmaría por primera vez eficazmente en América con la Constitución de Filadelfia de 1787 la que le otorgó la carta de ciudadanía en el Derecho Constitucional positivo. Su sistema de gobierno denominado presidencial, para distinguirlo del parlamentario, se caracteriza por la nítida distribución de las funciones a cargo de cada uno de los tres poderes constituidos del Estado. En la Constitución de los Estados Unidos se pueden ver recogidas y ampliadas las ideas expuestas por Montesquieu alrededor de cuarenta años antes, al punto que cada uno de los tres departa- 
mentos a quienes se encarga y atribuye la configuración del gobierno del Estado, tienen clara y concretamente delineadas sus funciones específicas. Verdaderamente, lo que se "conserva" de la idea desarrollada por Montesquieu es la necesidad de adoptar mecanismos que impidan la concentración del poder y que, además, permitan el control de su ejercicio. (V. Valadés, Diego, 2007, pp. 23-34).

El modelo constitucional estadounidense, concretamente, la ingeniería adoptada para llevar a cabo la distribución de los poderes y la asignación de sus competencias respectivas, es tenido muy en cuenta por los poderes constituyentes que dieron nacimiento a los Estados constitucionales en el siglo XIX en América Latina. Adoptan una posición más rígida todavía poniendo a resguardo a los titulares del Poder Ejecutivo ante los actos de control político del Congreso. Esta configuración rigurosa que persigue la intangibilidad del presidente de la República se acentúa en el momento constituyente originario de la Argentina de 1853-60.

La distribución del poder genera la aparición de departamentos gubernativos distintos, a quienes se encarga la formación de la voluntad estatal. La fragmentación de las funciones de los poderes estatales, tanto desde el punto de vista horizontal como vertical, desde una perspectiva normativa consiste en distribuir atribuciones entre poderes constituyentes y poderes constituidos, y luego entre Estado federal y provincias -corresponde agregar a partir de 1994 a la Ciudad de Buenos Aires-, y finalmente, generar las distintas competencias de los órganos e instituciones federales, concretada en el texto normativo de la Constitución federal. La técnica utilizada por los padres fundadores de la Constitución federal de la Argentina, insisto, en el plano estrictamente normativo, era uno de los antídotos más eficaces que se conocían a mediados del siglo XIX para evitar la concentración del poder y asegurar cierto espacio para la libertad de las personas.

\section{Experiencia constitucional}

Tal como se propuso al inicio, corresponde examinar el desarrollo que han observado las garantías políticas y las garantías jurídicas de la Constitución federal de la Argentina en los últimos 25 años.

Se trata, en rigor, en 155 años de historia constitucional, del primer período de 25 años en los que: todos los varones y mujeres que integran el cuerpo electoral han podido, sin restricciones, concurrir a las urnas para elegir y ser elegidos, sin haya existido quebrantamiento del orden constitucional.

\section{A. Sobre la división de poderes ${ }^{7}$}

$\S$ En 6 ocasiones se eligió Presidente y Vicepresidente de la Nación: 1983, 1989, 1995, 1999,2003 y 2007.

Se decide abandonar la pretensión de exhaustividad; o sea: no se menciona en qué año fue elegido tal o cual presidente de la República o se eligió o renovó a los miembros del Congreso de la Nación. Se adopta la determinación para privilegiar el acotamiento de la materia seleccionada. 
$\S$ En 13 oportunidades se han elegido Diputados de la Nación.

$\S$ Idénticamente, la integración y renovación de la Cámara de Senadores ha sido constitucionalmente adecuada.

$\S$ La Corte Suprema de Justicia de la Nación ha sido integrada en todo el período observando las reglas constitucionales. Alrededor de 20 magistrados, en todo el período han integrado el Tribunal. Se destaca, la reglamentación administrativa, a partir del año 2003 de la atribución presidencial para nominar los candidatos al Más Alto Tribunal de Justicia. A partir de dicho momento, de modo plausible, la consideración de la nominación, latamente, ingresa al auditorio público.

$\S$ El Ministerio Público, órgano constitucional extra-poder, se ha integrado respetando el procedimiento constitucional.

$\S$ Los órganos de control (Auditoría general y Defensor del Pueblo) también se han integrado cumpliéndose las reglas constitucionales.

\section{B. Reforma constitucional}

La reforma constitucional de 1994 fue la más amplia de todas las registradas en la historia. Gozó de mayor aceptación en todas las etapas del proceso constituyente, si se compara con sus dos predecesoras.

Veamos tres niveles.

El textual: de alrededor de 7.500 palabras se pasó a más de 12.500 , sin contar la jerarquía constitucional de las disposiciones contenidas en el derecho internacional de los derechos humanos a que hace referencia el artículo 75 , inciso 22 , de la CN.

El de las categorías jurídicas básicas: se expandieron por adición. Ingresaron nuevos derechos subjetivos y garantías, órganos de control, organismos de gobierno y se transfirieron competencias.

El dogmático: la reforma constitucional sancionada el 22/8/1994 acentuó notablemente las potestades del presidente -pese a crear la figura del Jefe de Gabinete de Ministros-; fijó acertadamente la forma de elección directa y el acortamiento de la duración del período; incorporó con jerarquía constitucional instrumentos del derecho internacional de los derechos humanos; se realizaron reformas sobre el modo de hacer las leyes, cuyos resultados no han sido muy visibles; replanteó el federalismo sobre bases bastante inciertas, pero muy razonablemente confirió autonomía a la Ciudad de Buenos Aires; reconoció nuevos derechos y garantías y actualizó el sistema axiológico manteniendo el piso originario; introdujo sensibles modificaciones sobre la naturaleza del poder judicial de la Nación al crear -con hibridez manifiesta- el Consejo de la Magistratura, circunstancia que se ha agudizado, recientemente, con la sanción de la ley 26.080; también introdujo como órgano extra poder independiente al Ministerio Público; intentando mejorar los controles incorporó el Defensor del Pueblo y la Auditoría General de la Nación; constitucionalizó la regla democrática reconociéndola como procedimiento básico que debe nutrir a la configuración del Derecho Constitucional y su manteni- 
miento -cfr. artículo 36 Constitución federal-, regulando, además, los partidos políticos, incorporando mecanismos de democracia semidirecta y la defensa del orden constitucional; se realizaron importantes esfuerzos para posibilitar que los estados locales creen regiones para el desarrollo económico y social; se define la autonomía municipal y se trazan bases rectoras para la integración con otros Estados soberanos.

\section{C. Federalismo}

$\S$ El pacto federal argentino se integra por 23 provincias y la Ciudad de Buenos Aires. En todos los casos, todos los poderes constituidos de los entes de la federación, se han integrado, de acuerdo a lo que ordenan las respectivas constituciones provinciales, sin interferencia ni limitación del poder federal.

$\S$ Los municipios, el tercer estadio de la descentralización del poder federal en la Argentina, se han integrado y desenvuelven sus atribuciones de acuerdo a las reglas previstas por la Constitución federal. En todos los casos, las elecciones han sido libres, sin objeciones.

$\S$ En contados casos se apeló a la intervención federal. Todos ellos justificados.

$\S$ La casi totalidad de las provincias puso en marcha el poder constituyente de segundo grado y reformó sus constituciones provinciales.

\section{Garantías de los derechos individuales}

“...No son, como puede creerse, las declaraciones, derechos y garantías, simples fórmulas teóricas: cada uno de los artículos y cláusulas que las contienen poseen fuerza obligatoria para los individuos, para las autoridades y para toda la Nación. Los jueces deben aplicarla en la plenitud de su sentido, sin alterar o debilitar con vagas interpretaciones o ambigüedades la expresa significación de su texto. Porque son la defensa personal, el patrimonio inalterable que hace de cada hombre, ciudadano o no, un ser libre e independiente dentro de la Nación Argentina...", dijo Joaquín V. González en 1897. (González, Joaquín V. 1897, p. 86.) La proposición citada, enfáticamente, corrobora la fuerza normativa de la Constitución, en particular, de las garantías tanto en su aplicación entre particulares como contra el Estado.

La CSJN tiene la última palabra en materia de control de constitucionalidad y resolución de conflictos. En la Argentina, los fallos de la Corte Suprema de Justicia de la Nación, dada la adopción del modelo de control de constitucionalidad difuso, no tienen efectos, en principio, para otros procesos que se desarrollen en otras jurisdicciones, ya sean federales o provinciales; la autoridad del fallo, pues, rinde en el proceso en que fue dictado; no obstante, los jueces que decidan apartarse de la doctrina oficial fijada por la CSJN deben aportar argumentos suficientes, bajo pena de nulidad. Esta construcción judicial emanada de la propia CSJN carece de soporte en el texto de la Constitución federal y elimina la discusión crítica y fomenta el creacionismo judicial, en detrimento de la división de poderes, ya que se priva al Congreso de la discusión de una materia constitucional. 
La elección de los 25 fallos que se ilustra más abajo, no es azarosa. Sin ninguna intención de hacer una inventario de la jurisprudencia del tribunal, una breve incursión por su repertorio jurisprudencial -la colección Fallos de la Corte Suprema de Justicia de la Nación- permite comprobar que hay determinados fallos, dentro de los miles y miles pronunciados en estos 25 años, que ningún análisis riguroso de su labor jurisprudencial debería dejar de ponderar. No afirmo que son los más importantes; en todos ellos se insinúa con firmeza, de una manera u otra -por acción porque la Corte lo hizo con acierto o con error, o por omisión porque la Corte debió hacerlo y no lo hizo-, el fenómeno del papel institucional del Tribunal. Algunos de los fallos que más abajo se citan, no deberían haber sido dictados jamás por la Corte, su demérito es tajante, especialmente por haberse renunciado a la custodia de la Constitución o favorecer la demolición uno o varios de los derechos fundamentales.

Invito entonces a repasar el listado cronológico de algunos leading cases de la Corte, los que inmediatamente luego de identificados por el nombre de las partes, consignan la fecha del pronunciamiento, permitiendo una lectura con algún sesgo histórico y, además, inmediatamente al lado la materia preferentemente examinada en el fallo. ${ }^{8}$ (V. Bazán, Víctor, 2008.)

Veamos.

- "Indalia Ponzetti de Balbín c. Editorial Atlántida S.A." (11/12/1984), Fallos 306: 1892 , derecho a la privacidad e intimidad.

- "Gustavo M. Bazterrica y Alejandro C. Capalbo" (29/8/1986), Fallos 308:1392, límites a la tarea legislativa y derecho de privacidad.

- "Causa originariamente instruida por el Consejo Supremo de las Fuerzas Armadas en cumplimiento del decreto del Poder Ejecutivo Nacional 158/1983" (30/12/ 1986), Fallos 309:5, condenas penales a ex dictadores del proceso militar 24/3/1976 a 10/12/1983, por graves violaciones a los derechos humanos: homicidios agravados, tormentos, privaciones ilegales de la libertad, y robos.

- "Ramón Juan Alberto Camps y otros" (22/6/1987), Fallos 310:1162, constitucionalidad legislación que dispuso la presunción juris et de jure de no punibilidad al personal militar de las Fuerzas Armadas que actuó desde el 24/3/1976 hasta el 26/9/ de 1983 en operaciones con motivo alegado de reprimir terrorismo.

- “José R. Dromi s/ avocación” (6/9/1990), Fallos 313:863, proceso de privatización de empresas estatales.

- "Luis Arcenio Peralta y otro v. Nación Argentina" (27/12/1990), Fallos 313:1513, emergencia pública, derecho de propiedad y fomento judicial del hiperpresidencialismo.

- "Miguel Angel Ekmedjian c. Gerardo Sofovich y otros" (7/7/1992), Fallos 315:1492, prioridad de rango del Derecho internacional convencional.

8 Básicamente, la mayoría de los fallos de la Corte Suprema de Justicia de la Nación pueden ser consultados libremente en el website www.csjn.gov.ar 
- "Horacio Giroldi y otro" (7/4/1995), Fallos 318:514, valor de la jurisprudencia de los tribunales internacionales para la interpretación de la Convención Americana de Derechos Humanos.

- “Carlos Santiago Fayt c. Nación Argentina” (19/8/1999), Fallos 322:1616, control de constitucionalidad de aspectos de una reforma constitucional.

- "Provincia de San Luis c. Nacional” (5/3/2003), Fallos 326:417, control de constitucionalidad de aspectos de la declaración de emergencia pública.

- "Enrique Lautaro Arancibia Clavel" (24/8/2004), Fallos 327: 3311, respeto a los derechos humanos e imprescriptibilidad de los crímenes de lesa humanidad.

- "Carlos A. Vizzoti”, (14/9/2004), Fallos 327:3677, reconocimiento judicial de la Constitución federal como norma jurídica y protección del derecho individual del trabajo.

- "Pedro C. F. Hooft c. Provincia de Buenos Aires", (16/11/2004), Fallos 327: 51 18, regla de razonabilidad e igualdad ante la ley.

- "Mabel Itzcovich c. ANSeS", (29/3/2005), Fallos 328:566, control de constitucionalidad de legislación sobre derecho de la seguridad social.

- "Julio H. Simón y otros", (14/6/2005), Fallos 328:2056, división de los poderes, vigencia de los derechos humanos, control de constitucionalidad de las leyes de punto final y obediencia debida.

- “Juan A. Massa c. Poder Ejecutivo Nacional”, (27/12/2006), Fallos 329:5913, responsabilidad del Estado, emergencia económica y derecho de propiedad.

- "Antonio Domingo Bussi c. Congreso de la Nación - Cámara de Diputados", (13/ 7/2007), Fallos 330:3160, división de los poderes, cuestión privativas no justiciables y elección popular de los miembros de los departamentos políticos.

- "Julio Lilo Mazzeo y otros", (13/7/2007), Fallos 330:3248, desaparición forzada de personas, positivización de los derechos humanos e inconstitucionalidad indulto presidencial delitos de lesa humanidad.

- "Celia María Ana Cambiaso Peres de Nealon y otros c. Centro de Educación Médica e investigaciones médicas”, (28/8/2007), Fallos 330: 3725, derecho a la salud.

- "Defensor del Pueblo de la Nación c. Nación Argentina y Provincia del Chaco", (18/9/2007), Fallos 330: 4134, suministro de agua y alimentos a indígenas en emergencia extrema.

- “Adolfo V. Badaro c. ANSeS”, (26/11/2007), Fallos 330: 4866, protección de la movilidad de los beneficios jubilatorios.

- "Editorial Río Negro c. Provincia del Neuquen", (5/12/2007), Fallos 330:3908, libertad constitucional de prensa.

- "Silvia Beatriz Mendoza y otros c. Estado Nacional", (8/72008), protección del ambiente.

- “Asociación de Trabajadores del Estado c. Estado Nacional y otro”, (11/11/2008), derecho de libertad de asociación sindical.

No se observa en el lenguaje de la Constitución ninguna preferencia hacia la garantía del proceso de gobierno sobre la garantía de los derechos individuales. La Constitución federal de la Argentina se realiza todos y cada uno de los días, felizmente, desde el 10/12/1983. Hay realización de la Constitución cuando los legisladores sancionan una ley, el juez pronuncia una sentencia, el presidente emite un decreto o un 
ciudadano transita libremente por un camino o decide presentar sus ideas en el auditorio público.

El Derecho constitucional federal de la Argentina, tal como se refiere más arriba, se compone de reglas que contienen o captan motivaciones dirigidas a la conducta humana. El Derecho constitucional no puede dejar de ser vinculado, pues, con la conducta humana. La fuerza normativa de la Constitución se encuentra condicionada, por decirlo de algún modo, con la posibilidad de realización de sus propias determinaciones. Cuanto mayor sea el grado de conexión de las reglas constitucionales con las circunstancias políticas e históricas, procurando conservar y desarrollar lo que encuentra diseñado en la regla constitucional del presente, tanto mejor conseguirán estos preceptos desplegar su fuerza normativa. (V. Hesse, Konrad, 1992, pp. 25-29.)

El Derecho constitucional de la Argentina, en el período 1983-2008, muestra, por lo tanto, una realización superior en tanto se refiere a la garantía del proceso de gobierno; las garantías de los derechos individuales necesitaron siempre una decisión, no que las realice, pero sí que las actualice cuando han sido puestas en entredicho!

\section{$\S \mathrm{V}$. COMENTARIO FINAL}

Antes de brindar una opinión final, es útil traer a colación una aguda observación de Eugenio Raúl Zaffaroni ${ }^{9}$ quien sostiene que, difícilmente, las garantías de los derechos individuales puedan realizarse si falta una adecuada separación de poderes y los contrapesos en el sistema, porque no hay garantía de que funcionen sin eso y, por lo tanto no habrá garantía de libertad. Una declaración de derechos revestida de un mágico sistema de garantías, descreo, que puede operar sin instituciones que puedan hacerla realidad y ante la cual pueda reclamarse por su desconocimiento. (V. Bianchi, Alberto, 1997).

Las garantías políticas, las garantías de la Constitución son primarias, en el sentido funcional y temporal. Funcionalmente: porque, básicamente, por intermedio de la división de poderes pueden crear ámbitos institucionales apropiados para el desarrollo de las garantías individuales. Temporalmente: porque en el diseño de la Constitución, si bien la libertad es un prius, primero se divide el poder y luego se detalla el status de las garantías individuales.

No obstante, queda claro que en el ámbito de la regulación normativa, la Constitución federal, las garantías políticas y las garantías jurídicas, tienen la misma altura jerárquica.

La Constitución federal es un instrumento destinado a la preservación de la libertad. De no ser así, no habría merecido que se luchara por ella. Ni en 1853. Ni en 1983.

9 El Prof. Dr. Eugenio Raúl Zaffaroni tuvo la generosidad de leer este documento, con antelación a su defensa pública. Agradezco, por supuesto, nuevamente, sus beneficiosos comentarios y observaciones. 
Entre 1983-2008 lo que ha distinguido a la Constitución federal de la Argentina ha sido un proceso de gobierno, antes que el congelamiento de valores sustantivos. De ninguna manera esta afirmación implica ingresar o tomar partido en la polémica entre textualistas v. contextualistas. Simplificadamente: un análisis de la realidad, basado en datos sobre el funcionamiento de las garantías de la constitución y las garantías de los derechos individuales.

Una de las peores crisis de la historia constitucional de la Argentina, la iniciada en 2001 , fue superada merced al "proceso" de gobierno estipulado en la Constitución federal: participación, publicidad y apertura a todos quienes de una forma u otra deseaban decidir o participar en las decisiones.

Examinado el período 1983-2008 los datos aportados vehiculizan el significado de que las garantías políticas han tenido un rendimiento más destacado que las garantías individuales. Ello, no significa, un rendimiento óptimo. Pone de manifiesto, en la comparación un mejor funcionamiento. Que quedaría demostrado, acabadamente, desde el mismo momento que en repetidas ocasiones, los ciudadanos y ciudadanas argentinos han concurrido a las urnas para elegir a sus representantes. Todo una novedad, en la práctica constitucional. Quedan, notables materias pendientes, entre ellas, el afianzamiento de los derechos individuales y el desarrollo de los grupales y colectivos, léase: educación y salud.

La Constitución federal garantiza el pluralismo político, núcleo de la libertad. La Constitución federal se ha mostrado como una regla abierta, capaz de asegurar que cualquier alternativa política que cumpla con las reglas mayores, acceda a la dirección del proceso gubernativo constitucional. Se dispone, por supuesto, de ámbitos reales de libertad, pero no funcionan, adecuadamente, los controles. Por ahora: una democracia constitucional procesal, con pocos controles.

La Constitución federal, tal como se anticipa en el punto II de esta exposición, se ha destacado por ser una regla procesal que garantiza la libre alternativa y alternancia política en el juego del poder. Ha permitido el libre acceso y ejercicio del poder de toda alternativa que se ha presentado. Ninguna alternativa, dentro de las cuatro esquinas del texto constitucional, ha sido prohibida. La Constitución federal, pues, se destaca por su desempeño procesal para garantizar la democracia. La afirmación no desdice la existencia de una ideación sobre los valores sustantivos en la Constitución; ciertamente, en la letra constitucional pueden existir y de hecho ocurre, empero, en el desarrollo constitucional, en la experiencia constitucional de día tras día, no se puede comprobar de modo incontrovertible que la tarea de preservar o congelar valores haya funcionado. En todo caso, de manera más modesta, un juicio empírico comprueba que la garantía del pluralismo, el núcleo de la libertad, ha operado para conformar la ordenación de las relaciones entre gobernantes y gobernantes. Resta mucho camino, todavía: el control efectivo de los titulares del poder y la efectiva vigencia de todas las garantías de los derechos individuales. 
Esta prevalencia de un aspecto de la garantía política, desgraciadamente, genera una consecuencia negativa. En la letra, la democracia constitucional argentina es representativa; es decir, el cuerpo electoral delega a ciertos y determinados servidores públicos la capacidad de hablar por ellos y tomar decisiones. Desde luego, la representación implica responsabilidad y rendición de cuentas por parte de los gobernantes. El representante es responsable ante quienes lo autorizaron a hablar en su nombre. Esta nueva categoría, la democracia delegativa, hace pie en el hecho de que la persona que gana la elección presidencial se encuentra autorizada a gobernar como le plazca, solo restringido por la cruda realidad emergente de las relaciones de poder existentes y por la limitación constitucional del término de su mandato. La democracia delegativa se desarrolla en el presidencialismo; el presidente es considerado la encarnación de la Nación y las medidas de gobierno no necesitan guardar parecido con los anuncios de la campaña electoral. Los presidentes, además, suelen verse a sí mismos como personajes por encima y por fuera del sistema de partidos y de los intereses comunitarios organizados. (O’Donnell, Guillermo, 1997).

En los escenarios de democracia delegativa, los partidos, el Congreso y la prensa son libres, pero constituyen, en un sentido fuerte, junto con los tribunales de justicia, un estorbo u obstáculo a la tarea del presidente, quien en su carrera hacia el absolutismo cree reunir el destino del país. Elegido el presidente, pues, en la democracia delegativa, es esperable que los delegantes ciudadanos complacientemente constituyan una audiencia pasiva de todo lo que haga el presidente.

Ciertamente, lo que diferencia marcadamente a la democracia delegativa de la democracia representativa es la debilidad de los controles. Como se dijera al inicio los controles interórganicos, horizontales, es decir una red de poderes relativamente autónomos que puedan examinar y cuestionar y de ser necesario sancionar actos irregulares cometidos durante el desempeño de los cargos públicos, no es puesto en funcionamiento o cuando se ejecuta es extremadamente débil en la democracia argentina.

La democracia delegativa es fuertemente mayoritaria. Consiste en producir, por intermedio de elecciones limpias una mayoría que autoriza a un presidente a convertirse en intérprete exclusivo de los intereses de la Nación. Luego de la elección, se espera que el elector-ciudadano-delegante vuelva a una audiencia pasiva y acrítica con el presidente. Esto conduce a un estilo mágico de hacer política: el mandato delegativo.

En la lógica de la delegación, las autoridades constitucionales, por la inexistencia de diálogo y control, pasan, muchas veces, de la omnipotencia a la impotencia.

Así, puede insinuarse una nueva tipología constitucional, las constituciones vulnerables y las que no lo son. Las primeras corresponden a comunidades donde predominan tendencialmente las actitudes hacia soluciones mágicas e irracionales. Allí las prescripciones del sistema constitucional pueden ser dejadas de lado, si es que ellas obstaculizan las políticas de turno. La política pocas veces es políticamente constitucional; siempre se intentará imponer la ley del más fuerte. Contrariamente, las constitu- 
ciones no vulnerables corresponden a sociedades cuya organización revela una natural tendencia al cumplimiento de las reglas básicas del juego constitucional preconfiguradas, siendo que estas encabezan la posibilidad de que cada ciudadano pueda cumplir racionalmente su plan de vida elegido.

La Constitución federal de la Argentina es imperfecta e incompleta. Aun con esa ausencia de perfección y totalidad, no tengo dudas en afirmar que el mundo de la democracia constitucional de la Argentina 1983-2008 es el mejor de todos los mundos políticos de cuya existencia histórica los argentinos han tenido conocimiento y constancia acreditada.

La Argentina cuenta con división de poderes. Tiene una democracia constituida. Y aunque los efectos estabilizadores y racionalizadotes de la Constitución potencian la vida comunitaria, no siempre se alcanza impedir el abuso del poder, tan propio de los sistemas de gobierno hiperpresidencialistas.

La división de poderes es una de las más importantes invenciones de la modernidad. Si ha de ser cierto, como observa Peter Häberle, que podría hablarse de un derecho fundamental a la división de poderes, ya que se encuentra al servicio de los derechos humanos y la protección de la libertad del individu (V. Häberle, Peter, 2003 (b), pp. 193-224), hay razones sobradas para ser optimista porque se puede mejorar y desarrollar la naturaleza participativa en la forma de la toma de decisiones y ahondar las garantías individuales.

\section{BIBLIOGRAFÍA}

Aguiar de Luque, Luis (1993). "Los límites de los derechos fundamentales”, Revista del Centro de Estudios Constitucionales, 1993, (Madrid, Ed. Centro de Estudios Constitucionales), pp. 9-34.

Alberdi, Juan Bautista. (1856). "Bases y puntos de partida para la organización política de la República Argentina”, en Organización política y económica de la Confederación Argentina, (Buenos Aires, Imprenta de José Jacquin, Besanzon), pp. 1-217.

BARKer, Robert (2005). La Constitución de los Estados Unidos y su dinámica actual. (Lima, Asociación Peruana de Derecho Constitucional; Instituto Iberoamericano de Derecho Constitucional).

BAZÁn, Víctor. (2008). "La reconfiguración del rol institucional de la Corte Suprema de Justicia argentina y el camino hacia su consolidación como tribunal constitucional”, en Anuario de Derecho Constitucional Latinoamericano 2008-14\%, (Montevideo Fundación Konrad Adenauer), pp. 25-61.

BianchI, Alberto. (2007). Una Corte liberal. La Corte de Alfonsín, (Buenos Aires, Ábaco). BidART Campos, Germán J (1995). El derecho de la constitución y su fuerza normativa, (Buenos Aires, Ediar).

Bоввıо, Norberto. (1997). Teoría general del Derecho, (Bogotá, Temis). 
BuLIGYN, Eugenio (2003). “Los jueces ¿crean Derecho?”, en la obra colectiva Función judicial. Ética y democracia, AA.VV, Jorge Malem, Jesús Orozco y Rodolfo Vázquez, compiladores, (Barcelona, Gedisa).

Bunge, Mario. (1981). Epistemología. Ciencia de la ciencia, (Barcelona, Ariel).

De Vergottini, Giuseppe. (2005). Derecho constitucional comparado, (traducción de Claudia Herrera), (Buenos Aires, Ed. Universidad).

Ely, John Hart (1997). Democracia y desconfianza. Una teoría del control constitucional, traducción de Magdalena Holguín, (Bogotá, Siglo del Hombre Editores).

GonzÁlez, Joaquín V. (1897). Manual de la Constitución Argentina, Buenos Aires.

Häberle, Peter. (2003). (a) "La constitución en el contexto”, en Anuario Iberoamericano de Justicia Constitucional, Centro de Estudios Políticos y Constitucionales, Número 7, (Madrid, Ed. Centro de Estudios Constitucionales), pp. 223-245.

HÄвERLE, Peter. 2003. (b) El Estado constitucional, Universidad Nacional Autónoma de México, Instituto de Investigaciones Jurídicas, estudio introductorio de Diego Valadés y traducción de Héctor Fix Fierro, (México, D.F.).

HesSE, Konrad. (1992). Escritos de Derecho constitucional, (selección, traducción e introducción Pedro Cruz Villalón), (Madrid, Centro de Estudios Políticos y constitucionales).

Kelsen, Hans. (1958). Teoría general del Derecho y del Estado, (traducción de Eduardo García Maynez), $2^{a}$ edición revisada, (México, Imprenta Universitaria, D.F.).

Loewenstein, Karl. 1979. Teoría de la constitución, (traducción de Alfredo Gallego Anabitarte), $2^{\text {a }}$ edición, reimpresión, (Barcelona, Ariel).

Montesquieu. 1900. Del espíritu de las leyes, Tomo I, (versión castellana de Nicolás Estévanez), (París, Casa Editorial Garnier Hermanos, circa).

O'Donnell, Guillermo. (1997). Contrapuntos. Ensayos escogidos sobre autoritarismo y democratización, $1^{\text {a }}$ edición, (Buenos Aires, Paidós).

Popper, Karl. (1995). Escritos Selectos, $1^{\text {a }}$ edición en español, (traducción de Sergio René Madero Baéz); David Miller, compilador, (México D.F., Fondo de Cultura Económica).

Russell, Bertrand (1999). "El realismo analítico", en Análisis filosófico, (introducción y traducción de Francisco Rodríguez Consuegra), (Barcelona, Paidós), pp. 66-74.

Russell, Bertrand (2004). Antología "Las formas del poder", 18 a edición, (traducción de Luis Echavarri), (Buenos Aires, Siglo XXI).

SAGüÉs, Néstor Pedro (2008). "Evolución institucional argentina: sistema de gobierno, poder judicial, derechos fundamentales 1975-2005”, Estudios constitucionales, Año 6, número 2, (Santiago, Centro de Estudios Constitucionales de Chile, Universidad de Talca), pp. 143-171.

Schmiтt, Carl (1992). Teoría de la constitución, $1^{\text {a }}$ reimpresión, (versión española de Francisco Ayala), (Madrid, Alianza Editorial).

Torres del Moral, Antonio. (2006). “Democracia militante”, en la obra colectiva Derecho constitucional para el siglo XXI. Actas del VIII Congreso Iberoamericano de Derecho constitucional, Tomo I, (Madrid, Thomson-Aranzadi), pp. 209-224.

Valadés, Diego: Parlamentarización de los sistemas presidenciales, Instituto de Investigaciones Jurídicas, Universidad Nacional Autónoma de México, 2007, México, D. F.

VAnossı, Jorge. (2000). Teoría constitucional. Teoría constituyente. Poder constituyente: fundacional, revolucionario, reformador, $2^{\text {a }}$ edición actualizada, Tomo I, (Buenos Aires, Depalma). 